\title{
Diagnosis and Management of Partial Thickness Rotator Cuff Tears
}

\author{
Saurabh Deore ${ }^{1 *}$, Milind Mehta ${ }^{2}$ and Sunil Garg ${ }^{3}$ \\ ${ }^{1}$ Norwich Medical school, University of East Anglia, UK \\ ${ }^{2}$ Orthopaedic Surgeon, Isle of Wight NHS Trust, UK \\ ${ }^{3}$ Consultant Orthopaedic Surgeon, James Paget University Hospital, UK
}

Submission: November 24, 2016; Published: December 09, 2016

*Corresponding author: Saurabh Deore, Medical Student, Norwich Medical School, University of East Anglia, 40 Dereham Road, Norwich, NR5 OSY, UK, Email: sdsaurabhdeore@gmail.com

\section{Abreviations}

PTRCT: Partial-Thickness Rotator Cuff Tears; ATI: Autologous Tenocyte Implantation; ASES: American Shoulder and Elbow Surgeons; UCLA: University of California, Los Angeles

\section{Introduction}

Shoulder pain is a common cause of morbidity in the society with surveys showing that $9-26 \%$ of the adult population being affected at a point in time [1]. It is the third most common cause of musculoskeletal pain in the community after back and knee pain. Shoulder pain usually indicates an underlying shoulder, neck or nerve pathology. Shoulder conditions causing pain can be broadly divided into rotator cuff disease, biceps tendon disease, acromioclavicular joint disease and glenohumeral pathology of adhesive capsulitis or arthritis [2]. In the subtype of rotator cuff disease, rotator cuff tendinopathy, subacromial bursitis, partialthickness rotator cuff tears (PTRCT) and full thickness tears are the common causes of pain and disability. The major cause of these conditions has been attributed to degenerative changes that come along with ageing. Full thickness rotator cuff tears have been studied, well recognized and managed very effectively. In contrast, the diagnosis and treatment of PTRCTs remains controversial. The purpose of this article is to define partial thickness tears, classify them, and discuss the pathophysiology, diagnosis and their management.

\section{Anatomy}

The rotator cuff is made up of 4 tendons - supraspinatus, infraspinatus, subscapularis and teres minor that arise from the scapula. The muscles move towards the humerus and along with the ligaments and other muscles help in shoulder stability and mobility. Much like the other tendons, most of the cuff is formed by type 1 collagen with proteoglycans, elastin, glycosaminoglycans and water. An area known as the 'critical zone' on the supraspinatus insertion has been said to have insufficient blood supply but in contrast Ultrasound Doppler studies have shown a normal supply in this region [3].

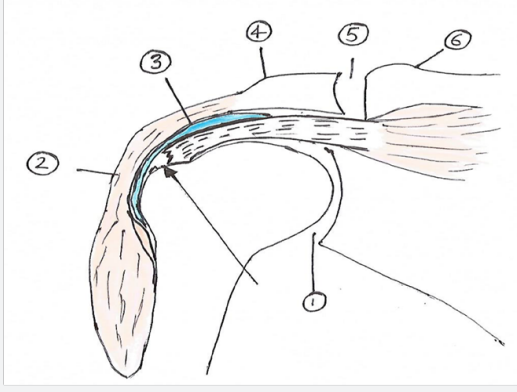

Figure 1: Partial thickness rotator cuff tears (the black arrow)

i. Glenohumeral joint,

ii. Deltoid muscle.

iii. Bursa

iv. Acromion,

v. Acromioclavicular joint and

vi. Clavicle

The insertion of the rotator cuff follows a consistent pattern Each tendon attaches to a bony landmark on the humerus to create a footprint. The four tendons of rotator cuff splay out and interdigitate into one tendon and insert onto the humeral head in a horseshoe shaped pattern. The supraspinatus has its 


\section{Orthopedics and Rheumatology Open Access Journal}

insertion on the greater tuberosity. Near its insertion the fibres of the supraspinatus and infraspinatus combine. The fibres of the subscapularis and supraspinatus enclose the biceps tendon. The subscapularis arises from the subscapular fossa and has its insertion on the lesser tuberosity beside the bicipital groove near the articular surface. Fibrous tissue originating from the coracohumeral ligament covers the anterior and bursal sides of the supraspinatus tendon. The infraspinatus surfaces from the infraspinatus fossa of the scapula and inserts onto the greater tuberosity. Some of its fibres fuse with supraspinatus and some fuse with teres minor [3-5] (Figure 1).

The superior insertion of the rotator cuff called the rotator cable looks like a thickened part of the capsule when seen from the glenohumeral joint. The cable is a deep extension of the coracohumeral ligament and made of fibrous tissue. This surrounds a thinner tissue area, consisting of the distal portions of supraspinatus and infraspinatus, called the crescent region that has its insertion at the greater tuberosity. This crescent region is contained within an avascular zone [6]. Most partial thickness tears tend to occur in this region. This rotator cablecrescent complex is believed to have stress-shielding properties (Figure 2).

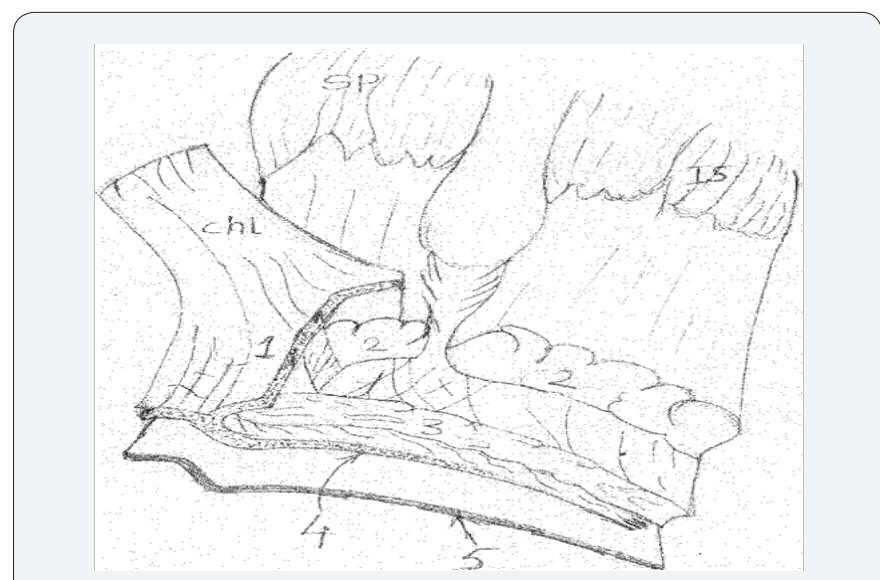

Figure 2:

The five histological layers at the insertion of the rotator cuff. SP - supraspinatus, IS - infraspinatus.

i. Superficial fibres of coracohumeral ligaments,

ii. Parallel cuff tendons to humeral insertion,

iii. Disorganised tendons, compared to layer two,

iv. Connective tissue perpendicular to tendon (rotator cable), v. Capsular layer with random fibre alignment [4].

The tendons of the supraspinatus and infraspinatus interdigitate in the posterior half of the supraspinatus tendon [7]. A recent study has suggested that the footprint of the supraspinatus was smaller than previously thought. The average maximum lengths reported were $6.9 \mathrm{~mm}$ medial to lateral and $12.6 \mathrm{~mm}$ anteroposterior. It was shown that the area of the greater tuberosity was occupied by a trapezoidal infraspinatus tendon which was also larger than previously estimated. The average maximum lengths reported were $10.2 \mathrm{~mm}$ medial to lateral and $32.7 \mathrm{~mm}$ anteroposterior. Thus, accounting for the high frequency of infraspinatus involvement even in previously thought isolated supraspinatus tears [8].

\section{Classification}

In 1983 the Neer classification described rotator cuff disease in 3 stages of impingement, with rotator cuff tears being classed in the final (3rd) stage. Partial thickness rotator cuff tears can be classified on three different bases - where they are located (articular, bursal or intratendinous), which tendon of the rotator cuff has been affected (supraspinatus, infraspinatus, teres minor or subscapularis) and the size of the tendon tear, calculated as a percentage of the thickness of the tendon [9]. The Ellman classification is based on arthroscopic intra-operative findings. A grade 1 tear is $<3 \mathrm{~mm}$ deep, a grade 2 tear is $3-6 \mathrm{~mm}$ deep and not more than $50 \%$ of the tendon thickness and a grade 3 is $>6 \mathrm{~mm}$ in depth or more than $50 \%$ of the tendon thickness [10]. This system has been simplified into two categories, $<50 \%$ or $<6 \mathrm{~mm}$ and $>50 \%$ or $>6 \mathrm{~mm}$. This classification is widely used to determine the treatment regime.

The Snyder [11] classification described the location, degree and size of the tear. The location being articular, bursal or a complete tear. PTRCTs were then further sub-classified as normal, grade 1, 2, 3 or 4. Grade 1 representing synovial irritation or capsular fraying in a small localised area usually less than 1 $\mathrm{cm}$. Grade 2 - a lesion with fraying and failure of some rotator cuff fibres along with synovial, bursal or capsular injury in an area of less than $2 \mathrm{~cm}$. Grade 3 - more severe rotator cuff injury with fragmentation of the tendon fibres in an area less than $3 \mathrm{~cm}$. Grade 4 - very severe injury with a sizeable flap, usually larger than $3 \mathrm{~cm}$, and involves more than one tendon [12]. The Ellman and Snyder classification both did not cover intratendinous tears and were intended mainly for arthroscopic examination.

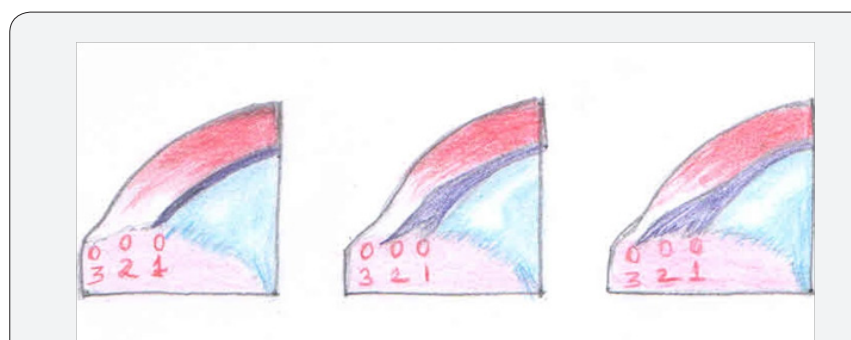

Figure 3: Habermayer classification Figure.

Habermayer proposed a new arthroscopic classification of articular-sided supraspinatus tears which includes determining the tear size, like the older classifications, this however also includes classification of the size and location of the tear in the sagittal and coronal plane. This system does not include bursal sided and intratendinous tears $[11,12]$. The Ellman classification is the most widely used and accepted system despite other systems being introduced (Table 1) (Figure 3). The Habermayer classification of partial thickness tears in the coronal plane. Longitudinal extension of articular sided supraspinatus tears in the coronal plane. Type 1 tear is a small tear at the changeover from cartilage to bone. Type 2 tear is a tear in the centre of the footprint and Type 3 is an extension of the tear to the greater tuberosity (Figure 4). 
Table 1: Classification of partial thickness rotator cuff tears [10-12].

\begin{tabular}{|c|c|c|c|c|c|}
\hline $\begin{array}{c}\text { Classification of } \\
\text { partial thickness } \\
\text { tears }\end{array}$ & & & & & \\
\hline $\begin{array}{c}\text { Ellman } \\
\text { Has not been } \\
\text { validated } \\
\text { Does not include } \\
\text { classification of } \\
\text { intratendinous tears }\end{array}$ & $\begin{array}{c}\text { Grade } 1,<3 \mathrm{~mm} \\
\text { or }<25 \% \text { of tendon } \\
\text { thickness }\end{array}$ & $\begin{array}{l}\text { Grade } 2,3-6 \mathrm{~mm} \text { or } \\
25-50 \% \text { of tendon } \\
\text { thickness }\end{array}$ & $\begin{array}{l}\text { Grade } 3,>6 \mathrm{~mm} \text { or } \\
>50 \% \text { of tendon } \\
\text { thickness }\end{array}$ & & \\
\hline $\begin{array}{c}\text { Snyder } \\
\text { (articular, bursal or } \\
\text { complete) } \\
\text { Has not been } \\
\text { validated } \\
\text { Does not include } \\
\text { classification of } \\
\text { intratendinous tears }\end{array}$ & 0 - normal & $\begin{array}{l}1 \text { - slight superficial } \\
\text { bursal or synovial } \\
\text { irritation or slight } \\
\text { capsular fraying over } \\
\text { a small area }\end{array}$ & $\begin{array}{l}2 \text { - Fraying and failure } \\
\text { of some rotator cuff } \\
\text { fibres in addition to } \\
\text { synovial, bursal or } \\
\text { capsular injury }\end{array}$ & $\begin{array}{l}\text { 3-More severe } \\
\text { rotator cuff } \\
\text { injury fraying and } \\
\text { fragmentation of } \\
\text { tendon fibres often } \\
\text { involving the whole } \\
\text { tendon cuff }\end{array}$ & $\begin{array}{l}\text { 4-Very severe partial } \\
\text { rotator cuff tear that } \\
\text { contains a sizeable } \\
\text { flap tear and more } \\
\text { than one tendon }\end{array}$ \\
\hline
\end{tabular}

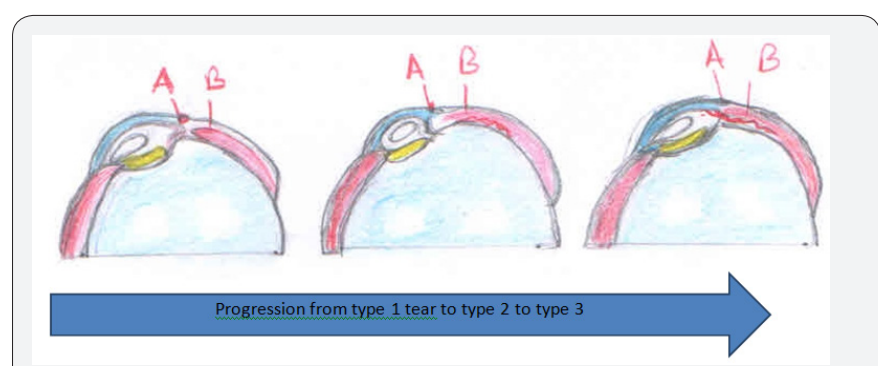

Figure 4: Progession from type 1 tear to type 2 to type 3.

The Habermayer classification of partial thickness tears in the sagittal plane. Sagittal extension of articular supraspinatus tendon tears in transverse plane. Type A tear is a tear in the coracohumeral ligament that continues into the medial border of the supraspinatus tendon. Type B tear is a tear isolated within the crescent zone. Type $\mathrm{C}$ tears are a tear extending from the lateral border of the pulley system over the medial border of the supraspinatus tendon up to the area of the crescent zone $[11,12]$.

\section{Incidence}

It has been known that the true prevalence of partial tears is much more than usually reported. Many of the people who have the tears are asymptomatic [13]. Cadaveric and imaging studies have shown that the prevalence of PTRCTs lies in the range of $13 \%-32 \%$ [14] and correlates with the patient's age significantly, $\mathrm{p}<0.05$. This has been supported by a MRI study showing a $20 \%$ overall prevalence of partial thickness tears in all age groups. However the prevalence of partial thickness tears in the age group above sixty was $26 \%$, age group forty to sixty was $24 \%$ and age group nineteen to thirty-nine years old was only $4 \%[15]$.

Reilly et al. [15] reported that $18.5 \%$ of the 2553 cadaveric shoulders studied had partial thickness rotator cuff tears. A study of 249 cadaveric supraspinatus tendons revealed that $7 \%$ had a full thickness tear whereas $13 \%$ had a PTRCT $(2.4 \%$ bursal sided, $3.6 \%$ articular sided and $7.2 \%$ intratendinous tears), suggesting the prevalence of partial thickness tears to be more than that of full thickness tears $[9,16]$. Amongst the three types of partial thickness tears intratendinous tears have been reported to be the most common, with a cadaveric study reporting $55 \%$ of all PTRCTs to be intratendinous tears [17]. Articular sided tears have been reported to be 2-3 times more common than bursal sided tears. It has been proposed that the cause for this in older patients is an area of hypo vascularity on the articular side that runs from the musculotendinous junction to within $5 \mathrm{~mm}$ of its insertion. The supraspinatus tendon has the highest incidence of tearing amongst the four rotator cuff tendons [18]. Thus tears commonly present on the articular side of the supraspinatus tendon $[19,20]$. A study with senior athletes, aged over 60 , showed that the prevalence of partial thickness was greater in athletes than in the general population of the same age [21]. Overall these results illustrate the importance of age as being an important factor in the prevalence of partial thickness rotator cuff tears.

\section{Pathology}

The pathology leading to the formation of PTRCTs is multifactorial. This can be intrinsic, extrinsic or traumatic [9]. Intrinsic factors include age related changes such as hypo cellularity, fascicular disruption, fascicular thinning, granulation tissue formation, dystrophic calcification and decreased vascularity and metabolic changes. Extrinsic factors include sub acromial impingement, internal impingement, glenohumeral instability and trauma [22-24]. Many studies have researched into microscopic changes and strain patterns. Fukuda, Hamada and Yamanaka [25] looked at 12 specimens with bursal-sided rotator cuff tears. Along with degeneration they noted disruption in the normal layer and increased vascularity at the site of tendon 
insertion. The proximal stump however was relatively avascular and rich in chondrocytes.

The superior shoulder capsule attaches to a large area (30\%-61\%) of the greater tuberosity. The capsule lies below the supraspinatus and infraspinatus tendons which also attach to the greater tuberosity. Thus it has been suggested that an articular sided tear can include a tear of the superior shoulder capsule and increase the likelihood of joint laxity. Biomechanical studies [18,26-28] have pointed out that the presence of PTRCTs alters the strain patterns within the remaining healthy tendon thus predisposing it to tear propagation [29]. A cadaveric study reported that the pathological and structural changes on the under surface of the acromion were associated with bursal sided tears. The incidence of acromial spurs has been reported to be the highest in bursal sided tears. In a study where all patients were presenting with impingement signs and sub acromial bursitis, many were noted to have type II or III acromion suggesting that subacromial impingement is a significant cause for bursal sided tears [30].

The majority of strain studies on intact tendons have reported that the strain is greater on the bursal side than on the articular side. It has been contemplated that the difference in the strain pattern contributes to a greater tear propagation in bursal sided infraspinatus tears. This can cause clinical consequences such that bursal sided tears are harder to treat with physical therapy (conservative). This was tested on sheep tendons. However, in a study on human supraspinatus tendons a similar pattern was observed where the transverse stiffness was greater on the bursal side than the articular side [31].

Many other factors are being proposed in the development of PTRCTs as more research is done. A risk factor for a PTRCT was suggested to be a tear in the contra lateral shoulder. The study showed that people with surgically treated rotator cuff tears had a higher prevalence of tears or a lack of functioning of the contra lateral shoulder [13]. Biopsies done on nine PTRCTs of the supraspinatus tendon, compared with healthy subscapularis tendon, showed an increased density of apoptotic p53+ tendon cells. This may relate to the healing process and has been suggested as a possible therapeutic target in the future [32]. A recent study ruled out any co-relation between macro vascular disease, atherosclerosis, and rotator cuff tears suggesting that vascular pathology is not a cause for rotator cuff disease or if it is, then it is likely to be micro vascular [33].

Collectively partial thickness rotator cuffs are caused by a combination of many factors. These factors are mostly age related but can also be due to extrinsic factors. It can be noted that conservative treatment may be a factor for poor prognosis of PTRCTs; however recognition of newer factors will be of therapeutic significance in the future.

\section{Diagnosis}

The diagnosis is based on the patient's presentation, physical examination and the use of diagnostic imaging.

Clinical history and Examination. The patient's usual presentation is with pain and discomfort. But this can widely vary in every patient with some complaining of chronic pain, shoulder instability and decreased throwing speed [34]. Examination of the shoulder can reveal painful arc syndrome, crepitus, impingement and loss of strength in the affected side [35]. This has a considerable overlap with other shoulder pathologies such as subacromial bursitis and with full thickness rotator cuff tears. Other tests done include the empty can test, full can test and drop arm test. A study found the sub acromial grind test, consisting of positive palpable crepitus on passive internal and external rotation of the shoulder while abducted in the scapular plane, to be useful in full thickness supraspinatus tears but not in PTRCTs [36]. There has been a long-standing association of rotator cuff pathology with sub-acromial volume, however, a MRI study with 46 patients found no relationship between the two. Sub-acromial volume is not yet reliable to help diagnose a rotator cuff tear [37]. Clinical findings should prompt imaging studies to give a better idea of the extent of the tear and its location. It is also known that many tears can be asymptomatic and thus association with imaging can be decisive.

\section{X-rays}

Radiographs were used to look for possible causes of rotator cuff disease in the past. They did not show any abnormalities in acute phases but pointed out the presence of sub acromialspurs. They can also show degenerative changes in the greater tuberosity of the head of humerus. These can be changes such as osteophytes, subchondral cysts, sclerosis and osteolysis [38]. These could be the potential causes for impingement of the rotator cuff.

\section{Ultrasound and MRI scan}

2-D sonography or ultrasound is a widely used technique in the diagnosis of rotator cuff tears, with accuracy between $87 \%$ and $96 \%$. The use of 3-D ultrasound has been reported to have a good inter-observer reliability in full thickness supraspinatus tears but not in PTRCTs. 3-D ultrasound has also shown to have a $17.4 \%$ greater sensitivity than 2-D ultrasound. However, these studies are limited by the number of participants and more data is needed [39].

A study done comparing ultrasound and MRI concluded that there was no difference between the two. The ultrasound detected $68.4 \%$ whilst MRI detected $63.2 \%$ of the PTRCTs. A metaanalysis done on 65 studies concluded that MR arthrography was more accurate than both MRI and ultrasound, whereas there was no difference between the sensitivity and the specificity for 
MRI and ultrasound. Although, it was also stated that ultrasound is more cost-effective and will save more time. In terms of MR arthrography, the risk of an invasive technique should always be considered [40]. The use of ultrasound in general is cheap and non-invasive however the diagnostic accuracy can be limited by the operator.

The diagnosis of intratendinous tears has been pointed out to be the most difficult to diagnose amongst the PTRCTs. Their accuracy of diagnosis has improved with the different MRI sequences and arm positioning. The signals include the linear high signal, within the tendon, that is along the tendon direction and focal defect at tendon insertion that does not communicate with either side of the tendon. A study done diagnosed close to $79 \%$ of intratendinous tears [17]. Other diagnostics used are direct MR arthrography and indirect MR arthrography. Although direct MR arthrography is more accurate in general, it is also more invasive and causes radiation exposure.

Indirect MR arthrography uses paramagnetic contrast media and has shown a sensitivity of diagnosing supraspinatus and infraspinatus partial tears to be $84 \%$ and $86 \%$ respectively [41]. Some studies have reported better diagnostic accuracy with indirect MR arthrography over the conventional MRI that does not use contrast $[42,43]$. Another meta-analysis and a systematic review have reported no difference in the sensitivity and specificity of MRI and ultrasound scans [44]. MR arthrography however was more accurate in the diagnosis of partial and full thickness tears. Thus, ultrasound has been recommended as the modality of use to recognise partial thickness tears but MR arthrography can be utilised if no other techniques provide a definitive diagnosis since this has the best sensitivity and specificity [40].

\section{Arthroscopy}

Arthroscopy allows a thorough assessment of tears with visualisation of the surrounding tissue and thus is the bestknown modality for diagnosis of bursal and articular sided tears. Once a diagnosis has been made the extent of the partial thickness tear needs to be determined. This has been done using an estimate of the bone exposed on the rotator cuff footprint with a reference shaver of a known size, which is compared with existing anatomical, clinical and radiographic data that is then used to generate a percentage. As this method is not accurate new methods have been suggested. The intra-articular depth guide is proposed to be used in bursal and articular sided tears. It is a device made with two parts, an inner probe which measures the size of the exposed footprint while the outer sleeve measures the tendon thickness. In a study on 8 cadavers it was found that the intra-articular depth guide was more accurate than the conventional method as it determined the total tendon thickness closer to the true anatomical measurements [45].
Arthroscopy is the gold standard in diagnosis of PTRCTs. However, this invasive procedure and generally performed concurrently with arthroscopic repair. Thus, the findings from ultrasound or MRI along with history and examination should be used collectively to make a clinical diagnosis.

\section{Treatment}

\section{Conservative Management}

Partial thickness rotator cuff tears are treated similarly to the patient with cuff tendinopathy and subacromial bursitis. Patients are often advised to avoid aggravating activates, take rest, apply heat modalities (ultrasound or heat), massage and take NSAIDs. In the early phases the use of steroid injections can be helpful. Once the inflammation and pain is under control more exercises can be performed to increase muscle strength. Free weights and rubber bands can be used with progressively increasing resistance to increase strength [9]. A recent study concluded that $91 \%$ of patients treated conservatively were content with their treatment at 46 months of follow up. It was also observed that patients without any history of shoulder trauma, non-dominant shoulder or tear less than $50 \%$ of tendon thickness were more likely to recover [46]. A clinical follow up study was done by Yamanaka \& Matsumoto [47] on 40 patients with partial thickness articular sided tears, diagnosed with arthrography and managed conservatively.

Arthrography repeated at a mean of 412 days revealed healing of the tear in 4 patients, reduction in size of the tear in 4 patients, larger tears size in 21 patients and progression to full thickness tears in 11 patients. Recently the use of hyaluronate injections has shown to be beneficial when compared to placebo but RCTs have found its effectiveness to be comparable with steroids $[48,49]$. Further research needs to be done to look at the long-term success of conservative management within groups with different factors such as age, intrinsic or extrinsic causes. Novel treatments such as ultrasound guided autologous tenocyte implantation (ATI), a bioengineered treatment, platelet-rich plasma and stem cell injections are being considered but need more research to be done before these can be implemented $[50,51]$.

\section{Surgical treatment}

Usually surgical intervention is indicated if conservative management has failed to control patient symptoms in the past 6 months, however earlier intervention may be necessary if significant functional disability is present. Other factors that are likely to affect this decision are the patient age, associated shoulder pathologies, occupation, activity level and the size of the tear [52]. Surgical treatment for PTRCTs includes debridement of the PTRCT with or without acromioplasty, arthroscopic management with trans-tendinous tear repair or conversion of the tear to a full thickness tear to be then repaired. 


\section{Debridement +/- Acromioplasty}

Debridement with or without acromioplasty is usually performed in low grade tears or tears that are less than $50 \%$ the tendon thickness. Acromioplasty has shown to have good outcomes in PTRCTs. Studies looking at debridement and sub-acromial decompression in PTRCTs have shown varying data with no clear benefit of one over the other. However, the procedure seems more likely to be successful in certain types of patients. A study done on 43 athletes under the age of 40 with a follow up of 2 years showed variability in the results. Athletes with acute injuries compared to the athletes who suffered a traumatic partial thickness tears had better outcomes (86\% vs. $66 \%$ respectively) when treated with debridement. The number of athletes who returned to play was also significantly greater (19\%) in the acute injuries group of patients [53].

A study in low grade tears showed no difference in bursalsided and articular sided-tears. Cordasco et al. [54] revealed good results in a study done on 77 shoulders but concluded that there was a significantly higher rate of failure in bursal-sided tears (29\%) compared to articular-sided tears (3\%) when treated with acromioplasty. Debridement and acromioplasty did not aid in healing of PTRCTs and the tears could potentially advance to form full thickness tears. This has been supported by Kartus et al. [55] who reported that $34.6 \%$ of partial thickness tears had progressed to a full thickness tears after a follow up of 8.4 years. This was in contrast to another study with acromioplasty and debridement which reported that only $6.5 \%$ repairs progressed into full thickness tears in patients with a mean age of 59.2 years [56]. A systematic review done on 16 studies concluded that debridement with or without acromioplasty had good outcomes in low grade tears but development of a further tear was a possibility [57]. It thus appears that debridement with or without acromioplasty has good outcomes for low grade tears and more likely to be useful in some patients but at the same time it does not prevent tear progression.

\section{Tear Conversion Followed by Repair}

A widely-used treatment of high grade bursal and articularsided PTRCTs involve its conversion to full-thickness tears followed by tendon repair. However, this method is thought to cause a mismatch between the length-tension aspect of the tear and the healthy part of the rotator cuff and thus increase re-tear rate. Studies done to compare tear conversion in bursal and articular sided tears have shown similar results in terms of the outcome, with one study reporting an equal or better outcome in bursal sided tears compared to articular sided tears. They did not show any difference in the tear rates on follow up [58,59]. A study done on 41 patients (42 shoulders) with high grade tears with an average age of 53 years reported $88 \%$ of complete repairs at 11 months. At follow up they observed that the average age of patients with progression to full thickness tears (62.6 years) was significantly higher compared to patients who did not have a tear progression (51.8 year) [60].

\section{In situ Repair}

This involves leaving the bursal sided cuff untouched while repairing just the torn articular sided region and thus theoretically has an advantage over the tear conversion technique as some of the anatomy is preserved. However, it has also been reported that the trans-tendon repair might have its flaws as it involves tying the bursal layer down and can cause over tightening of the bursal side. Newer studies have shown an all-inside technique with better post-operative results relating to the stiffness caused by over tightening [61]. Trans-tendon repair - This is a type of in situ repair technique widely used to treat articular sided tears. The trans-tendon repair technique has shown good improvement in functional outcomes after surgery as well [62]. Castricini et al. [63] treated 33 patients with the trans-tendon technique with an average33 month follow up period and reported an increase of more than $100 \%$ in the constant score before and after the surgery. Furthermore, no post-operative tears were reported.

Procedures performed from the bursal side are without visualisation, thus a new trans-tendon repair technique using arthroscopy and bursoscopy at the same time for partial thickness articular surface rotator cuff tears has been presented. It has better visualisation and thus reduces the probability of complications in surgery. However, a larger study needs to be done [64]. The trans-tendon repair has been attributed to causing stiffness and thus newer techniques have been suggested. A study done on 20 patients with high grade tears reported high levels of success, only 1 patient not returning to their previous level of activity, when treated with a new allinside repair technique [63] this high rate of repair has been supported by other studies $[65,66]$ (Table 2$)$.

Table 2: Trans-tendon vs. tear conversion.

\begin{tabular}{|c|c|c|c|c|c|}
\hline Author & $\begin{array}{l}\text { Number of patients } \\
\text { (before loss to } \\
\text { follow up) }\end{array}$ & Treatment & Intact repair \% & $\begin{array}{l}\% \text { Patients satisfied } \\
\text { or returned to } \\
\text { normal activity }\end{array}$ & \\
\hline & & & & & $\begin{array}{l}\text { Follow up time in } \\
\text { months }\end{array}$ \\
\hline Kamath et al. & 41 & Tear conversion & $88 \%$ & & 11 \\
\hline Castricini et al. & $31(33)$ & Trans-tendon repair & $100 \%$ & & 33 \\
\hline Spencer & 20 & Trans-tendon repair & & $95 \%$ & 29 \\
\hline
\end{tabular}




\section{Orthopedics and Rheumatology Open Access Journal}

\begin{tabular}{|c|c|c|c|c|c|}
\hline Castagna et al & $54(70)$ & Trans-tendon repair & & $98 \%$ & 32.4 \\
\hline Waibl and Buess & 22 & Trans-tendon repair & & $91 \%$ & 16 \\
\hline
\end{tabular}

Many studies have looked at the differences in trans-tendon and tear conversion techniques. Biomechanical studies have shown a higher ultimate load failure in patients with transtendon repair compared to tear conversion in articular sided PTRCTs [16]. Kim et al. [67] compared the in-situ repairs versus tear conversion with repair for partial thickness tears and concluded that there was an increase in functional outcomes and visual analogue scores regardless of the technique used with no significant difference in the two procedures. However, the retear rate for bursal-sided tears was higher in the group treated with tear conversion. The re-tear rate for articular sided PTRCTs was not different. This was supported by another RCT that pointed out that both, trans-tendon repair and tear conversion with repair, had similar outcomes clinically and on imaging in articular sided PTRCTs [49]. Another systematic review on arthroscopic management of partial thickness rotator cuff tears concluded that there was no difference in the two techniques. However there was a worse prognosis in bursal sided tears than articular sided tears [57].

A meta-analysis comparing the two techniques in articular sided tears of more than $50 \%$ thickness found no difference in the ASES (American Shoulder and Elbow Surgeons) score but noted a lower re-tear rate in the trans-tendon repair. It was also recognized that the patients complained of more pain and had a slower recovery back to functionality after the trans-tendon repair [19]. Repair with tear conversion might have its own flaws as it requires sacrificing a tendon that might be healthy. Furthermore, it is harder to restore the native tendon footprint in the anatomical position. These factors can render this type of repair to fail $[49,62]$. It was reiterated how trans-tendon repair may have its flaws, where pulling the retracted tendon onto the footprint can cause tightening in the bursal side and thus cause mechanical changes. This has been attributed to the painful lengthy recovery time of these repairs and might also explain the higher chance of developing stiffness in that shoulder [68].

Thus, it can be inferred that the trans-tendon technique works better in articular sided tears which are more than $50 \%$ thickness, and in general has similar outcomes to the tear conversion technique. Although it does appear that trans-tendon repair has a lower re-tear rate than tear conversion technique.

\section{Double Row vs. Single Row Repair}

Double row suture-bridge rotator cuff repair is a technique that has been shown to be more effective when compared to single row repair by many biomechanical studies. The former technique is shown to have a more enhanced, pressurized contact area between the tendon and footprint and decreased gap formation. Recently, the modified Mason-Allen single-row technique using triple-load anchors has been tried. A cohort study showed that this method had similar re-tear rates and functional outcomes as the double-row suture bridge technique in bursal-sided PTRCTs. The benefit of the Mason-Allen singlerow technique is that it used lesser suture anchors [69].

The arthroscopic knotless inverted-mattress technique was shown to have a re-tear rate of $5 \%$ in PTRCTs after a retrospective cohort study of 1000 cases. This was however performed by a single surgeon [70]. It is still not clear one technique is preferred over the other. There has been contrasting evidence as some studies report no difference, anatomically or clinically, whereas other studies suggest that double row repair has improved outcomes. A meta-analysis of 7 studies reported no difference in the outcome score however there was a significant increase in imaging-diagnosed re-tear rates in the single-row repair technique [71]. A review of 6 studies reported lower re-tear incidence after double row repair compared to single row repair in partial thickness tears, however it also stated that the functional outcome (measured using American Shoulder and Elbow Surgeons (ASES) shoulder score, the Constant shoulder score, and the University of California, Los Angeles (UCLA) score) were not better than the other in any of the techniques [72].

\section{Intratendinous Tears}

The surgical treatment of intratendinous tears has been rarely studied. They have been reported to be hard to diagnose using either ultrasound or MRI. A study done on intratendinous partial thickness tears showed a high rate of healing after arthroscopic repair [17]. Uchiyama et al. [73] did a study on intratendinous tears and concluded that conservative therapy had no effect on the tear. However, the outcomes were satisfactory (ASES average score 91.0 ) in 18 out of the 19 patients when surgically treated with anterior acromioplasty, excision and tenorrhaphy of the tear [73].

\section{Conclusion}

The presentation of partial thickness rotator cuff tears is a common shoulder problem prevalent within many age groups. Although new classification systems have been suggested, the older Ellman system remains to be used. Diagnostic techniques like ultrasound currently have shown good results and the accuracy is only going to get better with MR arthrography. Currently, the management of partial thickness tears still remains controversial with doubts over which patients to be treated conservatively or surgically and which type of surgery would be the most beneficial for various factors such as age and type of tear. This would need further research with larger groups to establish firmer guidelines. 


\section{Conflict of Interest}

Authors have no conflict of interest to declare.

\section{References}

1. M Urwin, D Symmons, T Allison, T Brammah, H Busby, et al. (1998) Estimating the burden of musculoskeletal disorders in the community: the comparative prevalence of symptoms at different anatomical sites, and the relation to social deprivation. Ann Rheum Dis 57(11): 649-55.

2. Linaker CH, Walker-Bone K (2015) Shoulder disorders and occupation. Best Pract Res Clin Rheumatol 29(3): 405-423.

3. Carr A, Harvie P (2005) Rotator cuff tendinopathy. In: Maffulli N, Renstro"m P, Leadbetter WB, ed. Tendon injuries. London: Springer 101-18.

4. Clark JM, Harryman DT (1992). Tendons, ligaments, and capsule of the rotator cuff. Gross and microscopic anatomy. J Bone Joint Surg Am 74(5): 713-725.

5. Curtis AS, Burbank KM, Tierney JJ, Scheller AD, Curran AR (2006) The insertional footprint of the rotator cuff: an anatomic study. Arthroscopy 22(6): 609.

6. Burkhart SS, Esch JC, Jolson RS (1994) The rotator crescent and rotator cable: an anatomic description of the shoulder's "suspension bridge". Arthroscopy 9(6): 611-616.

7. Andarawis-Puri N, Ricchetti ET, Soslowsky LJ (2009) Interaction between the supraspinatus and infraspinatus tendons: effect of anterior supraspinatus tendon full-thickness tears on infraspinatus tendon strain. Am J Sports Med 37(9): 1831-1839.

8. Mochizuki T, Sugaya H, Uomizu M, Maeda K, Matsuki K, et al. (2008) Humeral insertion of the supraspinatus and infraspinatus. New anatomical indings regarding the footprint of the rotator cuff. J Bone Joint Surg Am 90(5): 962-969.

9. Fukuda $H$ (2003) The management of partial-thickness tears of the rotator cuff. J Bone Joint Surg Br 85(1):3-11.

10. Ellman H (1990) Diagnosis and treatment of incomplete rotator cuff tears. Clin Orthop Relat Res 254: 64-74.

11. Belangero, Paulo Santoro, Benno Ejnisman, Guillermo Arce (2013) "A Review of Rotator Cuff Classifications in Current Use". Shoulder Concepts: Consensus and Concerns 2013: 5-13.

12. Habermeyer P, Krieter C, Tang KL, Lichtenberg S, Magosch P (2008) A new arthroscopic classification of articular-sided supraspinatus footprint lesions: a prospective comparison with Snyder's and Ellman's classification. J Shoulder Elbow Surg 17(6): 909-913.

13. Liem D, Buschmann VE, Schmidt C, Gosheger G, Vogler T, et al. (2014) The prevalence of rotator cuff tears: is the contralateral shoulder at risk? Am J Sports Med 42(4): 826-830.

14. Sher JS, Uribe JW, Posada A, Murphy BJ, Zlatkin MB (1995) Abnormal findings on magnetic resonance images of asymptomatic shoulders. J Bone Joint Surg Am 77(1): 10-15.

15. Reilly P, Macleod I, Macfarlane R, Windley J, Emery RJ (2006) Dead men and radiologists don't lie: a review of cadaveric and radiological studies of rotator cuff tear prevalence. Ann R Coll Surg Engl 88(2): 116-121.

16. Graeme Matthewson, Cara J. Beach, Atiba A. Nelson, Jarret M. Woodmass, Yohei Ono, et al. (2015) Partial Thickness Rotator Cuff Tears: Current Concepts. Adv Orthop 2015: 458786.

17. Jian Xiao, Guo-Qing Cui (2015) Clinical and Magnetic Resonance Imaging Results of Arthroscopic Repair of Intratendinous Partialthickness Rotator Cuff Tears. Chin Med J (Engl) 128(11): 1496-1501.

18. Bey MJ, Ramsey ML, Soslowsky LJ (2002) Intratendinous strain fields of the supraspinatus tendon: Effect of a surgically created articular- surface rotator cuff tear. J Shoulder Elbow Surg 11(6): 562-569.

19. Lin Sun, Qiang Zhang, Heng'an Ge, Yeqing Sun, Biao Cheng (2015) Which is the best repair of articular-sided rotator cuff tears: a metaanalysis. J Orthop Surg Res 10: 84.

20. Ahmed S. Eid, Amitabh J. Dwyer, Andrew F. W. Chambler (2012) Midterm results of arthroscopic subacromial decompression in patients with or without partial thickness rotator cuff tears. Int J Shoulder Surg 6(3): 86-89.

21. McMahon PJ, Prasad A, Francis KA (2014) What is the prevalence of senior-athlete rotator cuff injuries and are they associated with pain and dysfunction? Clin Orthop Relat Res 472(8): 2427-2432.

22. Ozaki J, Fujimoto S, Nakagawa Y, Masuhara K, Tamai S (1988) Tears of the rotator cuff of the shoulder associated with pathological changes in the acromion. A study in cadavera. J Bone Joint Surg Am 70(8): 12241230.

23. Uhthoff HK, Hammond DI, Sarkar K, Hooper GJ, Papoff WJ (1988) The role of the coracoacromial ligament in the impingement syndrome. A clinical, radiological and histological study. Int Orthop. 12(2): 97-104.

24. Ogata S, Uhthoff HK (1990) Acromial enthesopathy and rotator cuff tear. A radiologic and histologic postmortem investigation of the coracoacromial arch. Clin Orthop Relat Res 254: 39-48.

25. Fukuda H, Hamada K, Yamanaka K (1990) Pathology and pathogenesis of bursal-side rotator cuff tears viewed from en bloc histologic sections. Clin Orthop Relat Res 254: 75-80.

26. Nelly Andarawis-Puri, Eric T. Ricchetti, Louis J. Soslowsky (2009) Rotator cuff tendon strain correlates with tear propagation. J Biomech 42(2): 158-163.

27. Mazzocca AD, Rincon LM, O'Connor RW, Obopilwe E, Andersen M, et al. (2008) Intra-articular partial-thickness rotator cuff tears: analysis of injured and repaired strain behavior. Am J Sports Med 36(1): 110-116.

28. Reilly P, Amis AA, Wallace AL, Emery RJ (2003) Supraspinatus tears: propagation and strain alteration. J Shoulder Elbow Surg 12(2): 134138.

29. Mihata T, McGarry MH, Ishihara Y, Bui CN, Alavekios D, et al. (2015) Biomechanical analysis of articular-sided partial-thickness rotator cuff tear and repair. Am J Sports Med 43(2): 439-446.

30.Xiao J, Cui G (2015) Clinical and structural results of arthroscopic repair of bursal-side partial-thickness rotator cuff tears. J Shoulder Elbow Surg 24(2): e41-e46.

31. Frisch KE, Marcu D, Baer GS, Thelen DG, Vanderby R (2014) The influence of partial and full thickness tears on infraspinatus tendon strain patterns. J Biomech Eng 136(5): 051004.

32. Lundgreen K, Lian $\emptyset$, Scott A, Engebretsen L (2013) Increased levels of apoptosis and p53 in partial-thickness supraspinatus tendon tears. Knee Surg Sports Traumatol Arthrosc 21(7): 1636-1641.

33. Andrea Donovan, Mark Schweitzer, Jenny Bencardino, Catherine Petchprapa, Jodi Cohen, et al. (2011) Correlation between Rotator Cuff Tears and Systemic Atherosclerotic Disease. Radiol Res Pract 2011: 128353.

34. Franceschi F, Papalia R, Del Buono A, Maffulli N, Denaro V (2011) Repair of partial tears of the rotator cuff. Sports Med Arthrosc 19(4): 401-408.

35. Ponce BA, Kundukulam JA, Sheppard ED, Determann JR, McGwin G, et al. (2014) Rotator cuff crepitus: could Codman really feel a cuff tear? J Shoulder Elbow Surg 23(7): 1017-1022.

36. Seif Sawalha, Jochen Fischer (2015) The accuracy of "subacromial grind test" in diagnosis of supraspinatus rotator cuff tears. Int J Shoulder Surg. 9(2): 43-46. 


\section{Orthopedics and Rheumatology Open Access Journal}

37. Anthony Yi, Ioannis A Avramis, Evan H Argintar, Eric R White, Diego C Villacis, et al. (2015) Subacromial volume and rotator cuff tears: Does an association exist? Indian J Orthop 49(3): 300-303.

38. Bhagwani S, Peh WC (2013) Clinics in diagnostic imaging. 148. Bursalsided partial-thickness supraspinatus tendon tear. Singapore Med J 54(9): 524-529.

39. Hayter CL, Miller TT, Nguyen JT, Adler RS (2012) Comparative analysis of 2-versus 3-dimensional sonography of the supraspinatus tendon. J Ultrasound Med 31(3): 449-453.

40. de Jesus JO, Parker L, Frangos AJ, Nazarian LN (2009) Accuracy of MRI, MR arthrography, and ultrasound in the diagnosis of rotator cuff tears: a meta-analysis. AJR Am J Roentgenol 192(6): 1701-1707.

41. Lee JH, Yoon YC, Jee S (2015) Diagnostic performance of indirect MR arthrography for the diagnosis of rotator cuff tears at 3.0 T. Acta Radiol 56(6): 720-726

42. Yagci B, Manisali M, Yilmaz E, Ozkan M, Ekin A, et al. (2001) Indirect MR arthrography of the shoulder in detection of rotator cuff ruptures. Eur Radiol 11(2): 258-262.

43. Dinauer PA, Flemming DJ, Murphy KP, Doukas WC (2007) Diagnosis of superior labral lesions: comparison of noncontrast MRI with indirect MR arthrography in unexercised shoulders. Skeletal Radiol 36(3): 195202.

44. Dinnes J, Loveman E, McIntyre L, Waugh N (2003) The effectiveness of diagnostic tests for the assessment of shoulder pain due to soft tissue disorders: a systematic review. Health Technol Assess 7(29): iii, 1-166.

45. Michael J. Carroll, Kristie D. More, Stephen Sohmer, Atiba A. Nelson, Paul Sciore, et al. (2013) The use of an intra-articular depth guide in the measurement of partial thickness rotator cuff tears. Adv Orthop 2013: 959305 .

46. M.Denkers, K. Pletsch, R. Boorman, R.Hollinshead, and I.K. Y (2012) Lo, "Partial thickness rotator cuff tears: observe or operative," in Proceedings of the American Academy of Orthopaedic Surgeons Annual Meeting, San Francisco, Calif, USA.

47. Yamanaka K, Matsumoto T (1994) The joint side tears of the rotator cuff. A follow up study by arthrography. Clin Orthop Relat Res 304: 6873.

48. Shibata Y, Midorikawa K, Emoto G, Naito M (2001) Clinical evaluation of sodium hyaluronate for the treatment of patients with rotator cuff tear. J Shoulder Elbow Surg 10(3): 209-216.

49. Chou WY, Ko JY, Wang FS, Huang CC, Wong T, et al. (2010) Effect of sodium hyaluronate treatment on rotator cuff lesions without complete tears: a randomized, double-blind, placebo-controlled study. J Shoulder Elbow Surg 19(4): 557-563.

50. Wang AW, Bauer S, Goonatillake M, Breidahl W, Zheng MH (2013) Autologous tenocyte implantation, a novel treatment for partialthickness rotator cuff tear and tendinopathy in an elite athlete.

51. Stefan Bauer, Allan Wang, Rodney Butler, Michael Fallon, Robert Nairn, et al. (2014) Reliability of a 3 T MRI protocol for objective grading of supraspinatus tendonosis and partial thickness tears. J Orthop Surg Res 9: 128.

52. Oh LS, Wolf BR, Hall MP, Levy BA, Marx RG (2007) Indications for rotator cuff repair: a systematic review. Clin Orthop Relat Res 455: 5263.

53. Payne LZ, Altchek DW, Craig EV, Warren RF (1997) Arthroscopic treatment of partial rotator cuff tears in young athletes. A preliminary report. Am J Sports Med 25(3): 299-305.

54. Cordasco FA, Backer M, Craig EV, Klein D, Warren RF (2002) The partial-thickness rotator cuff tear: is acromioplasty without repair sufficient? Am J Sports Med 30(2): 257-260.
55. Kartus J, Kartus C, Rostgård-Christensen L, Sernert N, Read J, et al. (2006) Long-term clinical and ultrasound evaluation after arthroscopic acromioplasty in patients with partial rotator cuff tears. Arthroscopy 22(1): 44-49.

56. Liem D, Alci S, Dedy N, Steinbeck J, Marquardt B, et al. (2008) Clinical and structural results of partial supraspinatus tears treated by subacromial decompression without repair. Knee Surg Sports Traumatol Arthrosc. 16(10): 967-972.

57. Strauss EJ, Salata MJ, Kercher J, Barker JU, McGill K, et al. (2011) Multimedia article. The arthroscopic management of partial-thickness rotator cuff tears: a systematic review of the literature. Arthroscopy 27(4): 568-580.

58. Kim SJ, Kim SH, Lim SH, Chun YM (2013) Use of magnetic resonance arthrography to compare clinical features and structural integrity after arthroscopic repair of bursal versus articular side partial-thickness rotator cuff tears. Am J Sports Med 41(9): 2041-2047.

59. Kim KC, Shin HD, Cha SM, Park JY (2014) Repair integrity and functional outcome after arthroscopic conversion to a full-thickness rotator cuff tear: articular-versus bursal-side partial tears. Am J Sports Med 42(2): 451-456.

60. Kamath G, Galatz LM, Keener JD, Teefey S, Middleton W, et al. (2009 ) Tendon integrity and functional outcome after arthroscopic repair of high-grade partial-thickness supraspinatus tears. J Bone Joint Surg Am 91(5): 1055-1062.

61. Spencer EE (2010) Partial-thickness articular surface rotator cuff tears: an all-inside repair technique. Clin Orthop Relat Res 468(6): 1514-1520.

62. Kyung Cheon Kim, Hyun Dae Shin, Soo Min Cha, Jun Yeong Park (2013) Clinical outcomes after arthroscopic trans-tendon suturebridge technique in partial-thickness articular-side rotator cuff tear. Knee Surgery, Sports Traumatology, Arthroscopy 21(5): 1183-1188.

63. R. Castricinir, N. Panfoli, R. NittoliS. Spurio, O. Pirani (2009) Transtendon arthroscopic repair of partial-thickness, articular surface tears of the supraspinatus: results at 2 years. Chir Organi Mov 93(S): 49-54.

64. Fukuta S, Amari R, Tsutsui T (2015) Double arthroscopic transtendon repair of partial-thickness articular surface tears of the rotator cuff: a surgical technique. J Orthop Surg (Hong Kong) 23(3): 395-397.

65. Castagna A, Delle Rose G, Conti M, Snyder SJ, Borroni M, et al. (2009) Predictive factors of subtle residual shoulder symptoms after transtendinous arthroscopic cuff repair: a clinical study. Am J Sports Med 37(1): 103-108.

66. Waibl B, Buess E (2005) Partial-thickness articular surface supraspinatus tears: a new transtendon suture technique. Arthroscopy 21(3): 376-381.

67. Kim YS, Lee HJ, Bae SH, Jin H, Song HS (2015) Outcome Comparison Between in Situ Repair Versus Tear Completion Repair for Partial Thickness Rotator Cuff Tears. Arthroscopy 31(11): 2191-2198.

68. Huberty DP, Schoolfield JD, Brady PC, Vadala AP, Arrigoni P, et al. (2009) Incidence and treatment of postoperative stiffness following arthroscopic rotator cuff repair. Arthroscopy 25(8): 880-890.

69. Shin SJ, Kook SH, Rao N, Seo MJ (2015) Clinical Outcomes of Modified Mason-Allen Single-Row Repair for Bursal-Sided Partial-Thickness Rotator Cuff Tears: Comparison with the Double-Row Suture-Bridge Technique. Am J Sports Med 43(8): 1976-1982.

70. Brian T.N. Le, Xiao L. Wu, Patrick H. Lam, George A.C. Murrell (2014) Factors predicting rotator cuff retears: an analysis of 1000 consecutive rotator cuff repairs. Am J Sports Med 42(5): 1134-1142.

71. Millett PJ, Warth RJ, Dornan GJ, Lee JT, Spiegl UJ (2014) Clinical and 
structural outcomes after arthroscopic single-row versus double-row rotator cuff repair: a systematic review and meta-analysis of level I randomized clinical trials. J Shoulder Elbow Surg 23(4): 586-597.

72. Shen C, Tang ZH, Hu JZ, Zou GY, Xiao RC (2014) Incidence of retear with double-row versus single-row rotator cuff repair. Orthopedics 37(11): e1006-1013.
73. Uchiyama Y, Hamada K, Khruekarnchana P, Handa A, Nakajima T, et al. (2010) Surgical treatment of confirmed intratendinous rotator cuff tears: Retrospective analysis after an average of eight years of follow-up. J Shoulder Elbow Surg 19(6): 837-846.
This work is licensed under Creative Commons Attribution 4.0 Licens

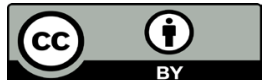

\section{Your next submission with Juniper Publishers} will reach you the below assets

- Quality Editorial service

- Swift Peer Review

- Reprints availability

- E-prints Service

- Manuscript Podcast for convenient understanding

- Global attainment for your research

- Manuscript accessibility in different formats

( Pdf, E-pub, Full Text, Audio)

- Unceasing customer service

Track the below URL for one-step submission https://juniperpublishers.com/online-submission.php 